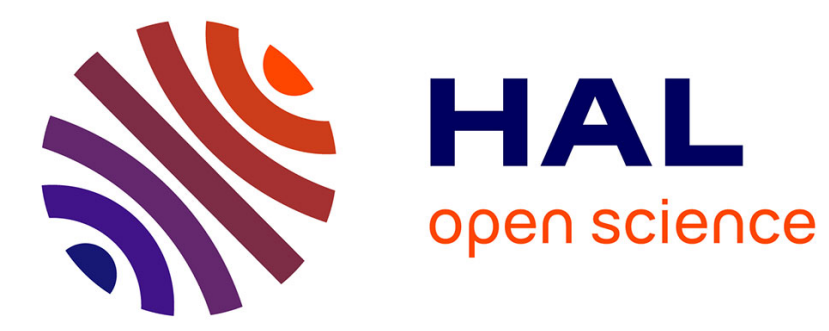

\title{
A XAFS Study on the Site Determination of Additives in the Ni3Al Intermetallic Compound
}

\author{
M. Sakurai, M. Matsuura, K. Suzuki, A. Chiba, S. Hanada
}

\section{To cite this version:}

M. Sakurai, M. Matsuura, K. Suzuki, A. Chiba, S. Hanada. A XAFS Study on the Site Determination of Additives in the Ni3Al Intermetallic Compound. Journal de Physique IV Proceedings, 1997, 7 (C2), pp.C2-1239-C2-1240. 10.1051/jp4:19972212 . jpa-00255285

\section{HAL Id: jpa-00255285 https://hal.science/jpa-00255285}

Submitted on 1 Jan 1997

HAL is a multi-disciplinary open access archive for the deposit and dissemination of scientific research documents, whether they are published or not. The documents may come from teaching and research institutions in France or abroad, or from public or private research centers.
L'archive ouverte pluridisciplinaire HAL, est destinée au dépôt et à la diffusion de documents scientifiques de niveau recherche, publiés ou non, émanant des établissements d'enseignement et de recherche français ou étrangers, des laboratoires publics ou privés. 


\title{
A XAFS Study on the Site Determination of Additives in the $\mathrm{Ni}_{3} \mathbf{A l}$ Intermetallic Compound
}

\author{
M. Sakurai, M. Matsuura*, K. Suzuki, A. Chiba** and S. Hanada \\ Institute for Materials Research, Tohoku University, Sendai 980, Japan \\ * Miyagi National College of Technology, Natori Miyagi 981-12, Japan \\ ** Faculty of Engineering, Department of Metallurgy, Iwate University, Morioka 020, Japan
}

\begin{abstract}
Occupied sites by dopants of $\mathrm{Ag}(0.1 \mathrm{at} \%), \mathrm{Pd}(2 \mathrm{at} \%)$ and $\mathrm{Zr}(0.4 \mathrm{ar} \%)$ in the $\mathrm{Ni3} \mathrm{Al}$ intermetallic compound are investigated by means of EXAFS analysis. It is found that Pd substitutes the $\mathrm{Ni}$ site and $\mathrm{Zr}$ substitutes the Al site. These results are consistent with those of channeling enhanced microanalysis. Ag is also determined to substitute in the Ni site by EXAFS and this result supports that $\mathrm{Ag}$ additive is $\gamma$-phase(disorder phase) former. The expansion of the nearest neighbor distance around $\mathrm{Ag}, \mathrm{Pd}$, and $\mathrm{Zr}$ are $2 \%, 3 \%$ and $4 \%$ respectively.
\end{abstract}

\section{INTRODUCTION}

Ni3 $\mathrm{Al}$ intermetallic compound having the $\mathrm{L}_{2}$ ordered structure is well known as a high temperature material. Lack of ductility of this $\mathrm{Ni} 3 \mathrm{Al}$ compound, however, restricts the application. To improve their ductility it has been found that the addition of the third elements are effective[1]. Chiba et. al. have found by channeling enhanced microanalysis that Pd has a strong tendency to substitute a Ni site independent of the composition of the host alloy. Furthermore, they have discovered that $\mathrm{Ag}$ also improves the ductility of the Ni3 Al compound. There are no experimental results, however, which site $\mathrm{Ag}$ substitutes in the NizAl because of experimental difficulty due to a small amount of $\mathrm{Ag}$ content $(<0.1 \mathrm{at} \%)$. The aim of this study is to determine the occupied site of the dilute dopants of $\mathrm{Ag}, \mathrm{Pd}$ and $\mathrm{Zr}$ in the Ni3Al by means of EXAFS and discuss about the lattice expansion around doping atoms.

\section{EXPERIMENTAL}

Three different doped Ni3Al samples were prepared: 0.1at\%Ag, 2at\%Pd and 0.4at\%Zr. The XAFS spectra of Pd, $\mathrm{Zr}$ and Ag $\mathrm{K}$-edge were obtained at the beam line BL6B of KEK Photon Factory with $3 \mathrm{GeV}$ operation mode. Fluorescence X-ray detection mode was applied for all specimens with using SSD as an X-ray detector to eliminate background signal due to elastic scattering and fluorescence X-rays emitted from Ni. Fe Filter was inserted in between the sample and the detector to minimize fluorescence $\mathrm{X}$-rays emitted from $\mathrm{Ni}$. All measurements have been done at room temperature and ring current was $120-190 \mathrm{~mA}$. The X-ray energy was defined by a Si(311) double crystal monochromator with sagittal focusing.

\section{RESULTS AND DISCUSSION}

Fourier transform $(F(t))$ of the Ag K-edge EXAFS for Ni3Al-0.1at\%Ag, the Pd K-edge EXAFS for Ni3A1-2at\%Pd and the Zr K-edge EXAFS for Ni3Al-0.4at\%Zr are shown in Fig.1. Fourier transformations are done on the $\mathrm{k}$ range of $3.5-12.5 \AA^{-1}$ for the Ag K-edge EXAFS and $3.5-16 \AA^{-1}$ for the Pd and the $\mathrm{Zr}$ K-edge EXAFS. It should be noted that F(r)'s of $\mathrm{Ag}$ and $\mathrm{Pd}$ EXAFS show a small peak around $3.2 \AA$ (pointed by the arrow in the figure). On the other hand, there are no peaks at this position in the $F(r)$ for $\mathrm{Zr}$ EXAFS. Chiba et. al. have reported that Pd has a strong tendency to substitute a Ni site while $\mathrm{Zr}$ substitute a Al site from channeling enhanced microanalysis[1]. By taking into account the results of the channeling enhanced microanalysis, it is obvious that the peak located at $3.2 \AA$ in the $F(r)$ is characteristic for Ni site in the Ni3Al intermetallic compound. The second shell around Ni site in the Ni3Al compound consists of $6 \mathrm{Ni}$ atoms with distance of $3.56 \AA$, while that around $\mathrm{Al}$ site has $6 \mathrm{Al}$ atoms with the same distance. Since an $\mathrm{Al}$ atom has small back scattering amplitude, it can be said that the peak corresponding to the second shell around Al site should be weak.

The differences in the $\mathrm{F}(\mathrm{r})$ between $\mathrm{Ni}$ and $\mathrm{Al}$ sites in the $\mathrm{Ni3} \mathrm{Al}$ compound are examined by theoretical calculation. Theoretical EXAFS calculations was carried out by applying program FEFF6[2] for the model structures of Ag. Pd and $\mathrm{Zr}$ atoms substitute $\mathrm{Ni}$ or $\mathrm{Al}$ site in the Ni3Al intermetallic compound. As shown in Fig. 2, there is a peak at $3.2 \AA$ in the $\mathrm{F}(\mathrm{r})$ for all the elements substituting the Ni site while no peak exists at $3.2 \AA$ for all elements substituting the Al site. The distance of the first shell around $\mathrm{Ni}_{\mathrm{i}}$ in ordered $\mathrm{Ni}_{3} \mathrm{Al}$ is $2.52 \mathrm{~A}$ and that of the second shall is $3.56 \AA$ for both of the Ni site and the Al site. 


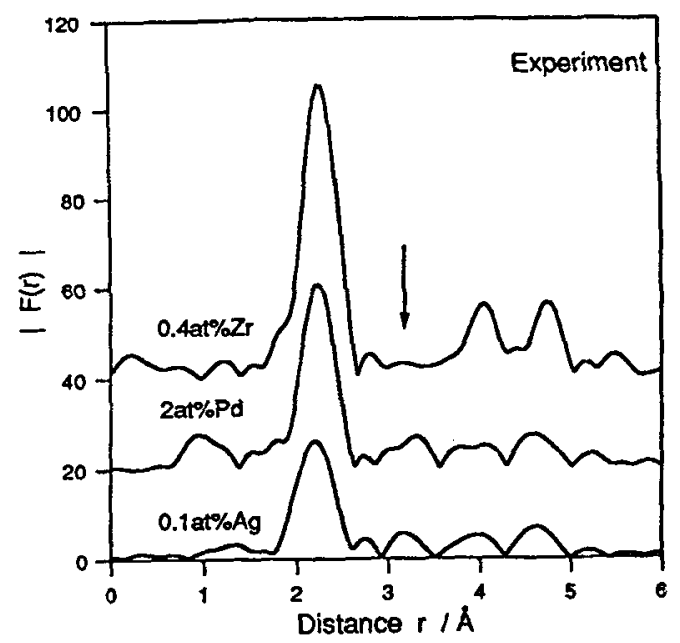

Figure 1: Magnitude of the Fouriet transform $F(r)$ for EXAFS of $0.1 \mathrm{at} \% \mathrm{Ag}$. 2at\% $\mathrm{Pd}$ and $0.4 \mathrm{at} \% \mathrm{Zr}$ dopants in the $\mathrm{Ni3} \mathrm{Al}$ compound. See details in text.

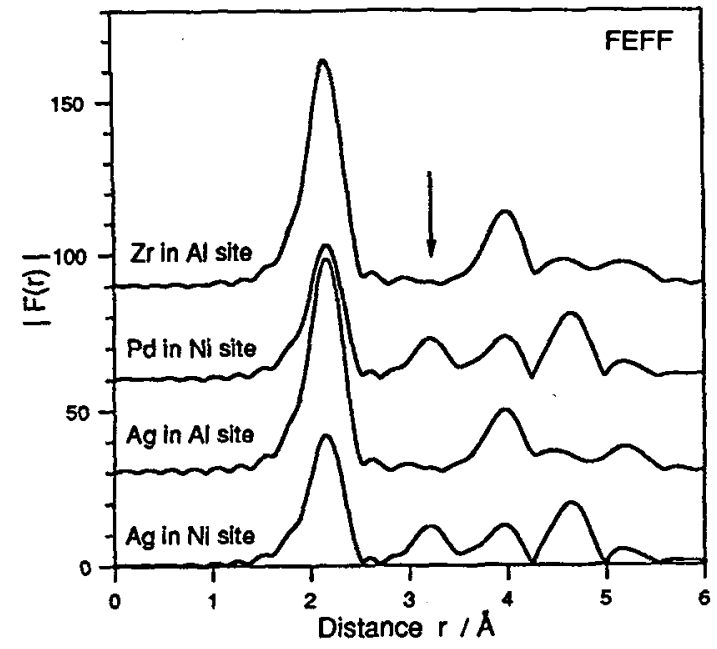

Figure 2: Magnitude of the Fourier transform $F(r)$ for EXAFS calculated by FEFF6[2] around Ag. Pd and $\mathrm{Zr}$ dopants in the $\mathrm{Ni3Al}$ compound with L12 structure. Substitute sites of these dopanis are indicated in the figure.

However, these theoretical calculations show no peaks at around $3.2 A$ for the $A 1$ site same as experimental results. Therefore this second correlation peak at $3.2 \AA$ in the $F(r)$ is characteristic for the dopants occupying the Ni site. Chiba et al. suggested that the ternary elements decreasing the ordering energy tend to substitute the $\mathrm{Ni}$ site while the elements increasing the ordering energy tend to substitute the Al site[3]. According to this classification, $\mathrm{Ag}$ and $\mathrm{Pd}$ substitute the $\mathrm{Ni}$ site and $\mathrm{Zr}$ substitute the Al site[3]. The experimental results of EXAFS for Ag, Pd and $\mathrm{Zr}$ dopants are consistent with these classification.

We use a simple substitution model in the FEFF calculation that atomic distances in the calculation are same as $\mathrm{Ni} 3 \mathrm{Al}$ compound. The positions of the first peak in the F(r) calculated by FEFF are $2.16 \AA$ for both of Pd and Ag dopants and $2.17 \AA$ for $\mathrm{Zr}$. On the other hand, experimental results show the position of the first peak at $2.21 \AA$ for Ag, $2.23 \AA$ for $P d$ and $2.26 \AA$ for $\mathrm{Zr}$. These results suggest that the dopants investigated in the present study give some stresses to Ni3Al lattice. The estimated expansion of the distance of the first nearest correlations are $2 \%$ for $\mathrm{Ag}, 3 \%$ for $\mathrm{Pd}$ and $4 \%$ for $\mathrm{Zr}$. The atomic radii of $\mathrm{Ni}$ and

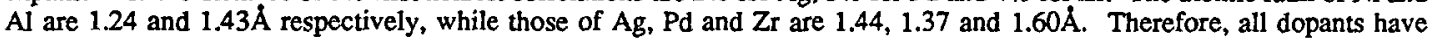
possibility to cause local lattice expansion. This is the first experimental observation about the expansion of the atomic distance caused by the dopant. It is still not clear, however, whether this lattice expansion is associated the ductility improvement.

In this system, degree of chemical ordering around doped atoms is important to discuss about the stability of ordered phase. The curve fitting results shows that the coordination number of $\mathrm{Al}$ and $\mathrm{Ni}$ around $\mathrm{Pd}$ atom are $5.0 \pm 0.5$ and $7.0 \pm 0.5$ respectively and that around $\mathrm{Ag}$ are $4.3 \pm 0.5$ and $7.7 \pm 0.5$ respectively. On the other hand, the first shell around $\mathrm{Ni}$ site is occupied by $4 \mathrm{Al}$ atoms and $8 \mathrm{Ni}$ atoms in the $\mathrm{Ni} 3 \mathrm{Al}$ compound. This higher coordination number of $\mathrm{Al}$ around $\mathrm{Pd}$ atom obtained from EXAFS is supported by the higher bonding strength of Pd-Al than Pd-Ni[4]. Consequently, it can be concluded that $\mathrm{Pd}$ dopnat tend to cause chemical disorder in the Ni3AI compound. The case of $\mathrm{Zr}$ dopant, EXAFS results shows that $\mathrm{Zr}$ atom is surrounded by $12 \mathrm{Ni}$ atoms then same as the local structure around $\mathrm{Al}$ site.

\section{Acknowledgments}

This work has been performed under the approval of the Photon Factory Program Advisory Committee(accepted No. 92G171).

\section{References}

[1] A. Chiba, S. Hanada and S. Watanabe, Acta metll., 39 (1991) 1799-1805.

[2] J.J. Rehr, J. Mustre, S.T. Zsbinsky and R.C. Albers, J. Am. Chem. Soc. B11(1991) 5135-5140.

[3] A. Chiba, S. Hanada and S. Watanabe, Scipta Metall., 25 (1991) 303-307.

[4] S.Ochiai, Y.Oya and T. Suruki, Acta metall., 32 (1984)1779-1805. 